\title{
Diabetes Burden in Urban and Rural Senegalese Populations: A Cross-Sectional Study in 2012
}

\author{
S. M. Seck, ${ }^{1}$ D. G. Dia, ${ }^{1}$ D. Doupa, ${ }^{1}$ A. Diop-Dia, ${ }^{1}$ I. Thiam, ${ }^{1}$ M. Ndong, ${ }^{2}$ and L. Gueye \\ ${ }^{1}$ Faculty of Health Sciences, Gaston Berger University, Saint-Louis, Senegal \\ ${ }^{2}$ Nutrition Department, Faculty of Agronomic Sciences, Gaston Berger University, Saint-Louis, Senegal \\ Correspondence should be addressed to S. M. Seck; sidy-mohamed.seck@ugb.edu.sn
}

Received 15 April 2015; Revised 11 July 2015; Accepted 13 August 2015

Academic Editor: Edward W. Gregg

Copyright (c) 2015 S. M. Seck et al. This is an open access article distributed under the Creative Commons Attribution License, which permits unrestricted use, distribution, and reproduction in any medium, provided the original work is properly cited.

\begin{abstract}
Diabetes represents a challenging global health issue in the 21st century. Data from sub-Saharan African populations are scarce and are usually restricted to urban settings. The objective of this study was to compare prevalence and risk factors of diabetes in rural and urban areas in Senegal. Methods. In a community-based survey between January and May 2012, we included 1027 adults aged $\geq 18$ years living in northern Senegal. Sociodemographic, clinical, and biological data were collected during household visits. Multivariate logistic regression was performed to identify factors associated with diabetes. Results. Mean age of participants was $48.0 \pm 16.9$ years and $65.7 \%$ were female. Participants from urban area represented $55.7 \%$. The age-standardized prevalence of diabetes was $7.6 \%$ (6.0\% in men versus $9.0 \%$ in women). Prevalence of diabetes was higher in urban areas (8.1\%) compared to rural areas $(4.6 \%)$. Disease awareness rate was $43 \%$. After multivariate analysis, age $(\mathrm{OR}=1.63, p=0.001)$, familial history of diabetes $(\mathrm{OR}=1.42, p=0.001)$, and abdominal obesity $(\mathrm{OR}=1.17, p=0.05)$ were associated with diabetes. Conclusion. Diabetes is frequent in urban and rural areas in Senegal. Awareness rate is very low among populations. Age, family history of diabetes, and abdominal obesity are the main risk factors identified.
\end{abstract}

\section{Introduction}

Diabetes represents a challenging health issue in the 21st century with a growing incidence estimated to be 381.8 million patients globally in 2013 and high morbidity and mortality rates [1]. Though population data are often scarce, the African continent is expected to bear the most important burden of diabetes during the next coming decades [1-3]. However, a few countries have developed national strategies to contain this coming epidemic [2]. In many cases, lack of data is the major barrier for setting up efficient programs for prevention and management of diabetes in disadvantaged populations. In Senegal, there is not yet available data on diabetes burden at national level but one recent survey in Saint-Louis city (northern region) reported a prevalence of $10.4 \%$ with two-thirds of patients uncontrolled [4]. Moreover, marked disparities had been reported between urban and rural regions where lifestyle habits and access to care are different [2-4].
The objective of this study was to compare prevalence and risk factors of diabetes in adult populations living in rural and urban areas in Senegal.

\section{Population and Methods}

2.1. Study Design. We performed a community-based crosssectional survey in Saint-Louis (northern region of Senegal). All individuals aged $\geq 18$ years and living in Saint-Louis for $\geq$ 3 months were eligible to participate in the study.

2.2. Sampling Procedure. A two-stage cluster sampling method was used to select a representative sample of adults living in urban and rural areas of Saint-Louis. We firstly selected 17 localities as clusters (9 urban areas and 8 rural areas). Then, we randomly took a number of households proportional to population size of each locality (data available from the National Agency of Statistics and Demography). 
From each household a maximum of two participants were randomly recruited among those present at the day of visit.

Considering $\alpha$-error of 0.05 and a power $\beta$ of $80 \%$, the required sample size was 855 individuals and we added a $20 \%$ attrition rate to get a sample of 1026 participants. Finally, a total of 1056 persons were sampled to enter the study.

2.3. Data Collection. Data were collected on site during house-to-house visits that were conducted between 7 a.m. and 12 p.m. or at the nearest health centre when patients did not live far away from this facility.

A modified version of the WHO STEPwise questionnaire (http://www.who.int/chp/steps/) was pretested and validated before its use to collect data. Researchers assisted by medical students, trained nurse practitioners, and community health workers had to fill the data collection form, to document the sociodemographic status (age, sex, marital status, education, profession, and education), personal and family health history (regarding, particularly, hypertension, diabetes, stroke, and heart and kidney disease), and lifestyle (nutritional habits, physical activity, smoking, and alcohol consumption) of each participant. Anthropometric measurements (weight, height, waist, and hip circumference) were performed using standard methods and calibrated devices. Blood pressure was measured twice at five minutes intervals by a semiautomatic sphygmomanometer and the mean of the two readings was calculated. If the difference between the readings was greater than $10 \mathrm{~mm} \mathrm{Hg}$, a third measurement was performed.

Hypertension was defined as a systolic blood pressure of $140 \mathrm{~mm} \mathrm{Hg}$ or more, diastolic blood pressure of $90 \mathrm{~mm} \mathrm{Hg}$, any prescription of antihypertensive medication in the past two weeks, or any self-reported history of hypertension [5]. Obesity was defined using International Diabetes Foundation cut-offs [6].

Serum total cholesterol, LDL cholesterol, HDL cholesterol, and triglycerides were measured with colorimetric method. Fasting blood glucose (FBG) was measured with a glucose oxidase method, and serum total cholesterol, HDL cholesterol, and total triglycerides were measured by an enzymatic calorimetric method. LDL cholesterol was calculated by the Friedewald formula. Diabetes was defined as FBG $\geq$ $126 \mathrm{mg} / \mathrm{dL}$ or by prescription of hypoglycemic agents despite fasting plasma glucose or any self-reported history of diabetes [6].

Physical inactivity was defined as less than 30 minutes of moderate activity per week or less than 20 minutes of vigorous activity three times per week, or the equivalent.

2.4. Statistical Analysis. Statistical analyses were performed with STATA 12.0 (Stata Corp, TX, USA). Continuous variables were presented as mean \pm standard deviation and categorical variables as percentage. Comparison of proportions and means were done using Pearson's Chi-square test or Student's $t$-test as appropriated. The age-standardized prevalence rates were calculated with the direct method, using the results of Senegalese general population census as the standard (http://www.ansd.sn/). Clinical and biochemical parameters associated with diabetes were assessed, in bivariate analysis,

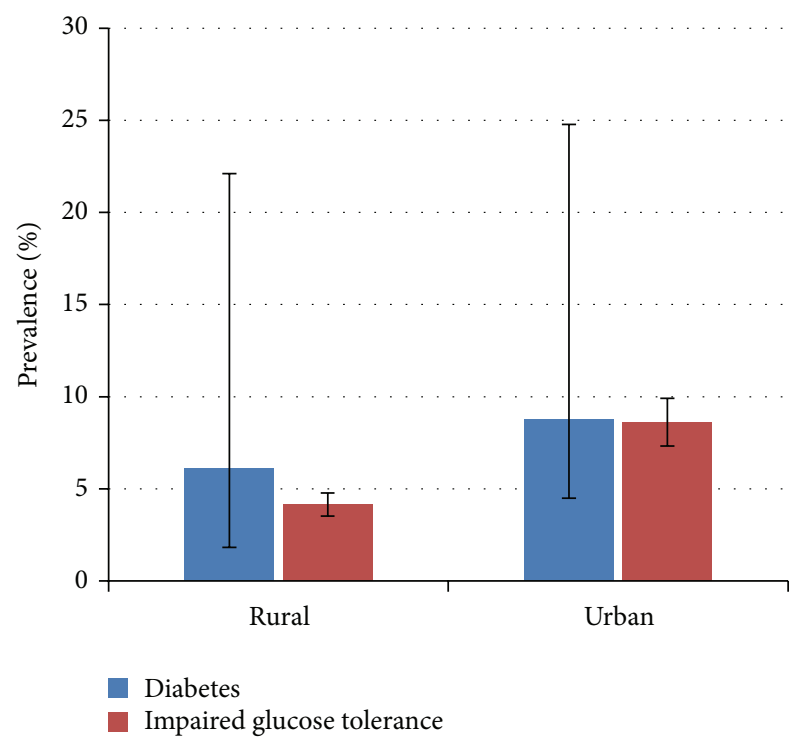

FIGURE 1: Prevalence of diabetes and impaired glucose tolerance in different settings.

comparing the group with diabetes and the group without diabetes using Student's $t$-test or a Chi-square test. Variables significantly associated with diabetes were then included in a multivariate logistic regression model with age, gender, and urbanization as forced variable. Odds ratio (ORs) with $95 \%$ $\mathrm{CI}$ and $p$ values of the final model are presented.

\section{Results}

A total of 1056 participants were involved in the study with a response rate of $99.1 \%$. But 21 of them were excluded from the analysis because of incomplete collected data and 1026 individuals were finally analyzed. The majority of patients (55.3\%) lived in urban area. The main clinical and biochemical characteristics are presented in Table 1.

The crude prevalence of diabetes in our sample was $10.8 \%$ (95\% CI: $6.9 \%-14.2 \%$ ). The age-adjusted prevalence of diabetes was $7.6 \%$ (95\% CI: $5.4 \%-10.5 \%$ ) with a difference between men $(6.0 \%)$ and women $(9.0 \%)$. The mean age of diabetic patients was $46.8 \pm 13.5$ years $(18-76$ years). The crude prevalence of diabetes in urban and rural settings was, respectively, $12.7 \%$ and $6.8 \%$. Adjusted prevalence of diabetes was higher in urban areas $(8.1 \%)$ compared to rural areas $(4.6 \%)$ (Figure 1 ). Also, in both settings, there was an increase in diabetes prevalence with age as shown in Figure 2. Comparing cardiovascular risk of people living in urban and in rural settings, we found similarly high prevalence of traditional cardiovascular risk factors such as hypertension, obesity, and physical inactivity contrasting with low proportion of smokers.

Regarding the disease awareness, $43 \%$ of patients were diagnosed during the survey, $36 \%$ were previously declared diabetic but without any medical follow-up, and $21 \%$ were regularly treated by a physician. 
TABLE 1: Clinical and biochemical characteristics of participants.

\begin{tabular}{|c|c|c|c|c|c|c|c|}
\hline & \multicolumn{2}{|c|}{ All participants $(n=1027)$} & \multicolumn{2}{|c|}{ Urban areas $(n=572)$} & \multicolumn{2}{|c|}{ Rural areas $(n=455)$} & \multirow{2}{*}{$p$ value } \\
\hline & Crude & Adjusted* & Crude & Adjusted $^{*}$ & Crude & Adjusted ${ }^{*}$ & \\
\hline Age (years) & $48.0 \pm 16.9(18-87)$ & & $51.6 \pm 15.7$ & & $43.5 \pm 17.2$ & & $<0.01$ \\
\hline Age group & & & & & & & $<0.01$ \\
\hline $18-34$ years & $25.6 \%$ & & $16.0 \%$ & & $37.8 \%$ & & \\
\hline $35-49$ years & $25.3 \%$ & & $26.1 \%$ & & $24.2 \%$ & & \\
\hline $50-60$ years & $23.6 \%$ & & $28.0 \%$ & & $18.1 \%$ & & \\
\hline$>60$ years & $25.5 \%$ & & $29.9 \%$ & & $19.9 \%$ & & \\
\hline School education & $60.7 \%$ & $52 \%$ & $63.4 \%$ & $47.5 \%$ & $55.6 \%$ & $45.8 \%$ & 0.19 \\
\hline Family diabetes history & $30.2 \%$ & $28.3 \%$ & $35.1 \%$ & $29.6 \%$ & $28.6 \%$ & $26.4 \%$ & 0.04 \\
\hline Fruits/vegetables consumption ( $\geq 3$ portions/day) & $39.0 \%$ & $36.7 \%$ & $42.3 \%$ & $40.5 \%$ & $34.6 \%$ & $25.6 \%$ & 0.05 \\
\hline Smoking & $4.2 \%$ & $2.9 \%$ & $5.2 \%$ & $3.1 \%$ & $2.8 \%$ & $1.7 \%$ & 0.05 \\
\hline Physical inactivity & $58.1 \%$ & $53.5 \%$ & $61.7 \%$ & $56.2 \%$ & $55.3 \%$ & $48.6 \%$ & 0.02 \\
\hline Hypertension & $39.1 \%$ & $32.1 \%$ & $43.3 \%$ & $36.8 \%$ & $33.8 \%$ & $29.2 \%$ & 0.08 \\
\hline Body mass index $\left(\mathrm{kg} / \mathrm{m}^{2}\right)$ & $26.3 \pm 6.8$ & $26.9 \pm 1.6$ & $27.9 \pm 7.3$ & $24.6 \pm 1.3$ & $24.1 \pm 5.5$ & $12.7 \pm 5.1$ & 0.03 \\
\hline Obesity & $23.4 \%$ & $20.5 \%$ & $33.8 \%$ & $31.6 \%$ & $10.2 \%$ & $9.4 \%$ & 0.01 \\
\hline Waist circumference $(\mathrm{cm})$ & $90.6 \pm 16.1$ & $90.1 \pm 8.2$ & $94.4 \pm 15.6$ & $91.6 \pm 10$ & $86.0 \pm 15.6$ & $82.4 \pm 8.5$ & 0.01 \\
\hline Abdominal obesity & $53.1 \%$ & $48.6 \%$ & $63.9 \%$ & $59.5 \%$ & $40.0 \%$ & $33.4 \%$ & 0.01 \\
\hline Total cholesterol (g/L) & $2.18 \pm 0.5$ & $2.15 \pm 0.1$ & $2.25 \pm 0.5$ & $2.61 \pm 3.2$ & $2.10 \pm 0.4$ & $2.08 \pm 1.1$ & $<0.01$ \\
\hline Hypercholesterolemia & $56.0 \%$ & $54.6 \%$ & $62.5 \%$ & $59.3 \%$ & $46.7 \%$ & $43.4 \%$ & 0.53 \\
\hline
\end{tabular}

${ }^{*}$ Adjusted for age.

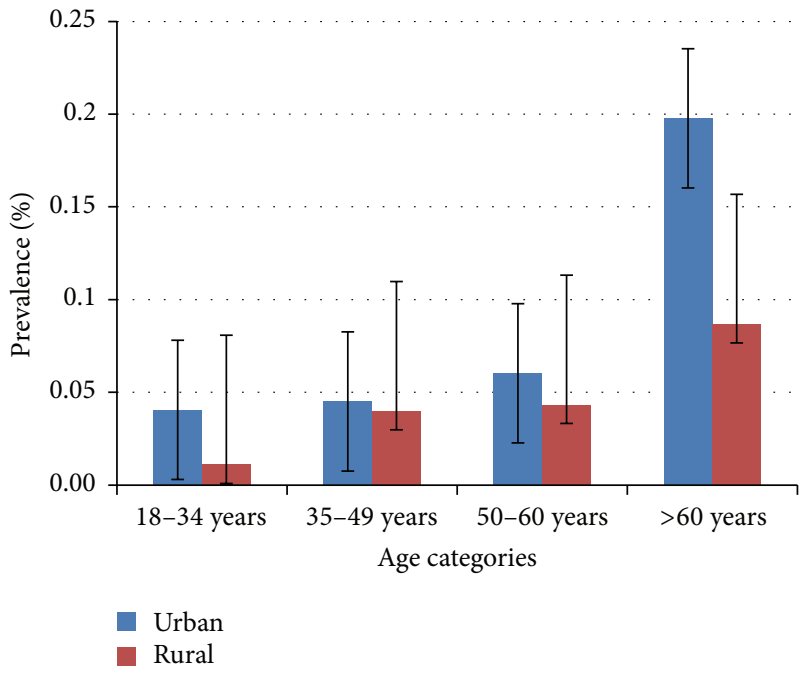

Figure 2: Age-specific prevalence of diabetes in urban and rural areas.

The presence of diabetes was associated with common risk factors like age, gender, obesity, and familial history of diabetes (see Table 2). Univariate analysis showed that age $\geq 35$ years ( $10 \%$ of diabetics versus $5.5 \%$ in people aged $<35$ years), female gender $(9.0 \%$ of diabetics versus $6.0 \%$ in males), family history of diabetes (diabetes prevalence of $8.4 \%$ versus $5.1 \%$ ), and obesity (diabetes prevalence of $13.9 \%$ versus $8.3 \%$ ) were significantly associated with a higher chance to get diabetes. Conversely, physical activity and daily consumption of $\geq 3$ fruits/vegetables were associated with lower risk of diabetes in this population (prevalence differences of $19.5 \%$ and $4.4 \%$, resp.). After adjustment for age, gender, smoking, familial history, and obesity, the risk of diabetes was similar in individuals living in urban area compared to those living in rural areas (they presented a diabetes risk excess of $27 \%)$. Only age $>35$ years $(\mathrm{OR}=1.63$, $95 \% \mathrm{CI}=[1.48-2.06])$, existence of family history of diabetes $(\mathrm{OR}=1.42,95 \% \mathrm{CI}=[1.12-3.77])$, and abdominal obesity $(\mathrm{OR}$ $=1.17,95 \% \mathrm{CI}=[1.00-1.78])$ remained significantly associated with diabetes (see Table 3 ).

\section{Discussion}

Prevalence of diabetes in sub-Saharan Africa is variable across countries, ethnic groups, and settings considered. Reported data from community-based studies range from $2.8 \%$ in rural populations in Angola [7] to $28.2 \%$ found in South African mixed ancestry populations living in urban areas $[8,9]$.

Epidemiological studies in rural populations are scarcer but they generally show a lower prevalence [10-12] compared to surveys in urban settings [13-15].

In this study, the prevalence of diabetes in urban areas is quite twice the one in rural areas. Comparable prevalence ratios (urban/rural) were found in Kenya [12] and in Democratic Republic of Congo [15].

As already reported in the literature, we found an increasing prevalence with age which is a major risk factor for type 2 diabetes [2].

Gender distribution of diabetes is also variable. Some studies found higher prevalence in men $[10,11]$ and others reported the contrary $[9,16]$. 
TABLE 2: Crude association between diabetes and risk factors (univariate analysis).

\begin{tabular}{|c|c|c|c|}
\hline & Odds ratio & [95\% confidence interval] & $p$ value \\
\hline Age group ( $<35$ versus $\geq 35$ yrs $)$ & 1.79 & $1.55-2.37$ & 0.001 \\
\hline Female gender & 1.14 & $1.05-3.28$ & 0.045 \\
\hline Family history of diabetes & 1.60 & $0.76-1.45$ & 0.001 \\
\hline School education & 0.88 & $0.70-1.00$ & 0.038 \\
\hline Fruits/vegetables consumption ( $\geq 3 /$ day) & 0.95 & $0.65-2.57$ & 0.244 \\
\hline Smoking & 1.05 & $0.92-2.68$ & 0.229 \\
\hline Physical inactivity & 1.22 & $0.45-2.96$ & 0.502 \\
\hline Hypertension & 1.29 & $0.61-3.64$ & 0.073 \\
\hline Obesity $\left(\mathrm{BMI} \geq 30 \mathrm{~kg} / \mathrm{m}^{2}\right)$ & 1.10 & $0.85-1.92$ & 0.309 \\
\hline Abdominal obesity & 1.66 & $1.40-2.03$ & 0.001 \\
\hline Living in urban setting & 1.40 & $1.10-2.47$ & 0.039 \\
\hline
\end{tabular}

BMI: body mass index.

TABLE 3: Adjusted association between diabetes and risk factors (multivariate regression analysis).

\begin{tabular}{lccc}
\hline & Odds ratio & [95\% confidence interval] & $p$ value \\
\hline Age group (<35 versus $\geq 35$ yrs) & 1.63 & $1.48-2.06$ & 0.001 \\
Female gender & 1.42 & $0.75-1.84$ & 0.108 \\
Fruits/vegetables consumption ( $\geq 3 /$ day) & 0.87 & $0.25-1.43$ & 0.326 \\
Family history of diabetes & 1.49 & $1.12-3.77$ & 0.001 \\
Physical inactivity & 1.04 & $0.54-3.56$ & 0.235 \\
School education & 1.02 & $0.33-1.92$ & 0.164 \\
Abdominal obesity & 1.17 & $1.00-1.78$ & 0.055 \\
Living urban setting & 1.27 & $0.65-2.34$ & 0.073 \\
\hline
\end{tabular}

$N=654$, Pseudo- $R^{2}=0.152$.

In the present study, female gender, absence of school education, and living in urban setting were associated with diabetes at univariate analysis. However, these associations were no longer significant after adjustment for true risk factors that were abdominal obesity, age, and familial history of diabetes.

As underlined in many studies, we found a higher prevalence of diabetes in women compared to men and this difference was more striking among rural populations.

The level of disease awareness is low in our study. However, these rates are better than what was reported in rural Tanzanians (8.3 to $13.2 \%)[17,18]$ or South Africans (15.3\%) [19] or in a previous survey in Dakar (capital city) where $90 \%$ of newly diagnosed diabetics were not aware of their disease [16].

Recent forecast suggests an alarming increase of diabetes incidence in Africa during the next decade in addition to other noncommunicable and infectious diseases [3]. In the US population between 1980 and 2011, the crude prevalence of diagnosed diabetes increased from $2.5 \%$ to $6.9 \%$ while ageadjusted prevalence rose in the same proportions indicating that changes in the population age structure do not explain the epidemic transition [20].

The true explanation of this rising burden of diabetes in both urban and rural Africa is probably multifactorial. With life expectancy increase, the most important part might be driven by lifestyle modifications (fast urbanization, physical inactivity, and dietary transition) which promote obesity and insulin resistance but also environmental and genetic factors have not been well explored [2]. Data on the changes in the $\beta$-cell function and insulin resistance in the early stages of the disease process in African populations are scarce [21]. A few genetic studies performed in small groups from northern and western Africa had identified some polymorphism associated with diabetes but epigenetic factors which should play an important role in the disease onset are still unknown [22-24].

Other conditions like HIV and sickle cell diseases are also incriminated in the current epidemics of diabetes in Africa $[25,26]$.

Despite its epidemiological importance of describing diabetes face in Senegalese populations, this study has many limitations. Firstly, the cross-sectional design is not suitable for inferential analysis about causality or direction of association between diabetes and other cardiovascular risk factors. Secondly, incidence of diabetes could not be calculated to estimate the disease potential progression in the population.

\section{Conclusion}

This study shows that diabetes is frequent in northern region of Senegal. Urban settings are more concerned than rural areas and prevalence is higher among women. The awareness rate is very low among populations. Age, familial history of diabetes, and abdominal obesity are the main risk factors 
identified. Prevention program targeting both urban and rural populations are urgently needed in African countries in order to reduce the morbidity and mortality due to diabetes.

\section{Ethical Approval}

The study was approved by the National Committee for Ethics in Health Research.

\section{Consent}

A free consent form had to be signed by participants to give their approval before data collection. All participants were personally informed of their screening results and those with abnormal values were referred to a specialist for further exploration and treatment.

\section{Conflict of Interests}

The authors declare that there is no conflict of interests regarding the publication of this paper.

\section{References}

[1] L. Guariguata, D. R. Whiting, I. Hambleton, J. Beagley, U. Linnenkamp, and J. E. Shaw, "Global estimates of diabetes prevalence for 2013 and projections for 2035," Diabetes Research and Clinical Practice, vol. 103, no. 2, pp. 137-149, 2014.

[2] A. P. Kengne, J.-B. Echouffo-Tcheugui, E. Sobngwi, and J.-C. Mbanya, "New insights on diabetes mellitus and obesity in Africa-part 1: prevalence, pathogenesis and comorbidities," Heart, vol. 99, no. 14, pp. 979-983, 2013.

[3] V. Hall, R. W. Thomsen, O. Henriksen, and N. Lohse, "Diabetes in Sub Saharan Africa 1999-2011: epidemiology and public health implications. A systematic review," BMC Public Health, vol. 11, article 564, 2011.

[4] S. Pessinaba, A. Mbaye, G.-À. Yabeta et al., "Prevalence and determinants of hypertension and associated cardiovascular risk factors: data from a population-based, cross-sectional survey in Saint Louis, Senegal," Cardiovascular Journal of Africa, vol. 24, no. 5, pp. 180-183, 2013.

[5] A. V. Chobanian, G. L. Bakris, H. R. Black et al., "The seventh report of the joint national committee on prevention, detection, evaluation, and treatment of high blood pressure: the JNC 7 report," Hypertension, vol. 42, pp. 1206-1252, 2003.

[6] International Diabetes Federation, The IDF Worldwide Definition of the Metabolic Syndrome, International Diabetes Federation, Brussels, Belgium, 2006, http://www.idf.org/webdata/ docs/IDF_Meta_def_final.pdf.

[7] A. D. Evaristo-Neto, M. C. Foss-Freitas, and M. C. Foss, "Prevalence of diabetes mellitus and impaired glucose tolerance in a rural community of Angola," Diabetology \& Metabolic Syndrome, vol. 2, article 63, 2010.

[8] R. T. Erasmus, D. J. Soita, M. S. Hassan et al., "High prevalence of diabetes mellitus and metabolic syndrome in a South African coloured population: baseline data of a study in Bellville, Cape Town," South African Medical Journal, vol. 102, no. 11, pp. 841844, 2012.
[9] N. Peer, K. Steyn, C. Lombard, E. V. Lambert, B. Vythilingum, and N. S. Levitt, "Rising diabetes prevalence among urbandwelling black South Africans," PLoS ONE, vol. 7, no. 9, Article ID e43336, 2012.

[10] E. C. Ejim, C. I. Okafor, A. Emehel et al., "Prevalence of cardiovascular risk factors in the middle-aged and elderly population of a nigerian rural community," Journal of Tropical Medicine, vol. 2011, Article ID 308687, 6 pages, 2011.

[11] S. Hammami, S. Mehri, S. Hajem, N. Koubaa, H. Souid, and M. Hammami, "Prevalence of diabetes mellitus among noninstitutionalized elderly in Monastir City," BMC Endocrine Disorders, vol. 12, article 15, 2012.

[12] G. B. Ploubidis, W. Mathenge, B. De Stavola, E. Grundy, A. Foster, and H. Kuper, "Socioeconomic position and later life prevalence of hypertension, diabetes and visual impairment in Nakuru, Kenya," International Journal of Public Health, vol. 58, no. 1, pp. 133-141, 2013.

[13] J. B. Echouffo-Tcheugui, A. Dzudie, M. E. Epacka et al., "Prevalence and determinants of undiagnosed diabetes in an urban sub-Saharan African population," Primary Care Diabetes, vol. 6, no. 3, pp. 229-234, 2012.

[14] S. Baragou, M. Djibril, B. Atta, F. Damorou, M. Pio, and A. Balogou, "Prevalence of cardiovascular risk factors in an urban area of Togo: a WHO STEPS-wise approach in Lome, Togo," Cardiovascular Journal of Africa, vol. 23, no. 6, pp. 309-312, 2012.

[15] P. Katchunga, B. Masumbuko, M. Belma, Z. Kashongwe Munogolo, M.-P. Hermans, and J.-R. M’Buyamba-Kabangu, "Age and living in an urban environment are major determinants of diabetes among South Kivu Congolese adults," Diabetes and Metabolism, vol. 38, no. 4, pp. 324-331, 2012.

[16] P. Duboz, N. Chapuis-Lucciani, G. Boëtsch, and L. Gueye, "Prevalence of diabetes and associated risk factors in a Senegalese urban (Dakar) population," Diabetes and Metabolism, vol. 38, no. 4, pp. 332-336, 2012.

[17] T. J. Aspray, F. Mugusi, S. Rashid et al., "Rural and urban differences in diabetes prevalence in Tanzania: the role of obesity, physical inactivity and urban living," Transactions of the Royal Society of Tropical Medicine and Hygiene, vol. 94, no. 6, pp. 637-644, 2000.

[18] D. G. Mclarty, A. B. Swai, H. M. Kitange et al., "Prevalence of diabetes and impaired glucose tolerance in rural Tanzania," The Lancet, vol. 333, no. 8643, pp. 871-875, 1989.

[19] A. A. Motala, T. Esterhuizen, E. Gouws, F. J. Pirie, and A. K. Mahomed, "Diabetes and other disorders of glycemia in a rural South African community: prevalence and associated risk factors," Diabetes Care, vol. 31, no. 9, pp. 1783-1788, 2008.

[20] Crude and Age-Adjusted Rate per 100 of Civilian, Noninstitutionalized Population with Diagnosed Diabetes, United States, 1980-2011, Division of Diabetes Translation, Centers for Disease Control and Prevention, National Center for Health Statistics, National Center for Chronic Disease Prevention and Health Promotion, 2015, http://www.cdc.gov/diabetes/ statistics/prev/national/figage.htm.

[21] A. G. Amoah, D. P. Schuster, T. Gaillard et al., "Insulin resistance, beta cell function and cardiovascular risk factors in Ghanaians with varying degrees of glucose tolerance," Ethnicity \& Disease, vol. 12, pp. S3-10-S3-17, 2002.

[22] R. Bouhaha, T. Baroudi, H. Ennafaa et al., "Study of TNF $\alpha$ 308G/A and IL6-174G/C polymorphisms in type 2 diabetes and obesity risk in the Tunisian population," Clinical Biochemistry, vol. 43, no. 6, pp. 549-552, 2010. 
[23] I. Ezzidi, N. Mtiraoui, R. Nemr et al., "Variants within the calpain-10 gene and relationships with type 2 diabetes (T2DM) and T2DM-related traits among Tunisian Arabs," Diabetes \& Metabolism, vol. 36, no. 5, pp. 357-362, 2010.

[24] G. Chen, A. Adeyemo, J. Zhou et al., "Genome-wide search for susceptibility genes to type 2 diabetes in West Africans: potential role of C-peptide," Diabetes Research and Clinical Practice, vol. 78, no. 3, pp. el-e6, 2007.

[25] I. J. Paik and D. P. Kotler, "The prevalence and pathogenesis of diabetes mellitus in treated HIV-infection," Best Practice \& Research: Clinical Endocrinology \& Metabolism, vol. 25, no. 3, pp. 469-478, 2011.

[26] V. Ama, A. P. Kengne, N. J. R. Nansseu, B. Nouthe, and E. Sobngwi, "Would sickle cell trait influence the metabolic control in sub-Saharan individuals with type 2 diabetes?" Diabetic Medicine, vol. 29, no. 9, pp. e334-e337, 2012. 


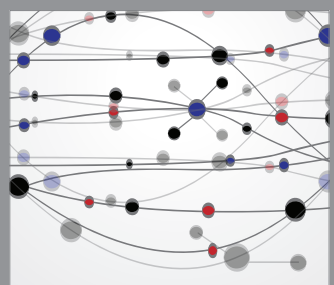

The Scientific World Journal
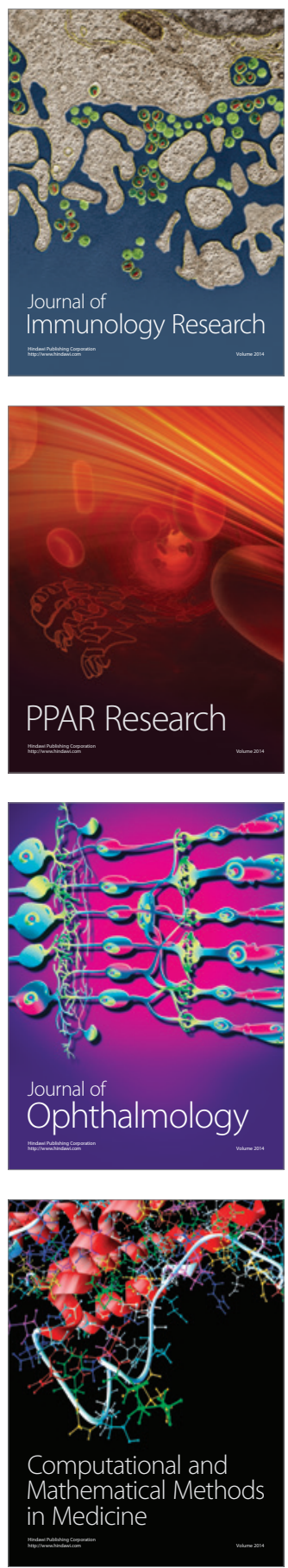

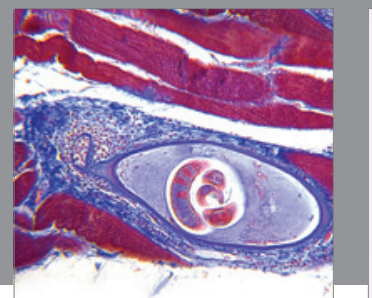

Gastroenterology

Research and Practice
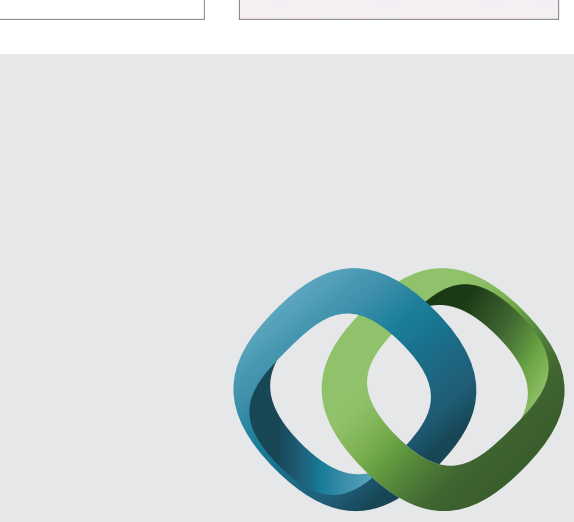

\section{Hindawi}

Submit your manuscripts at

http://www.hindawi.com
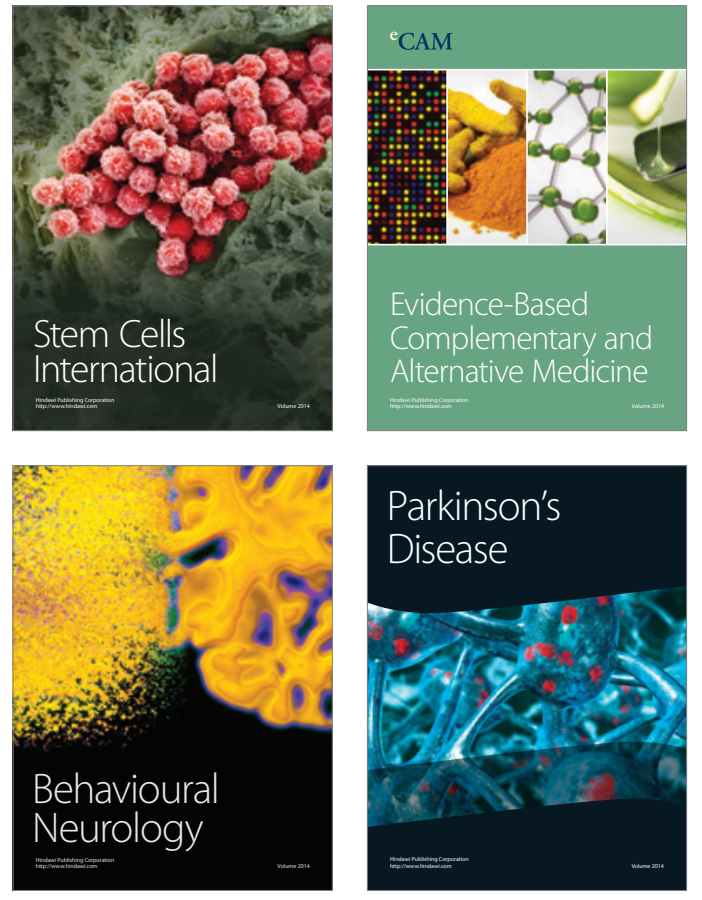
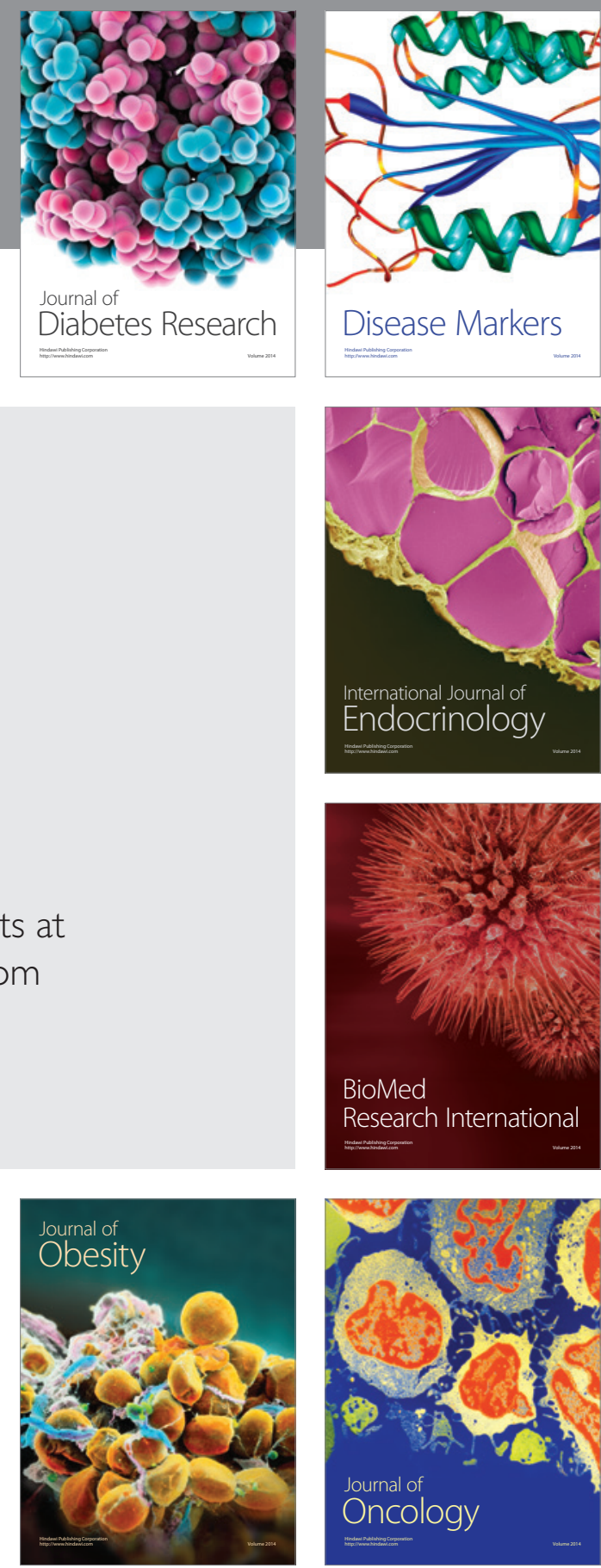

Disease Markers
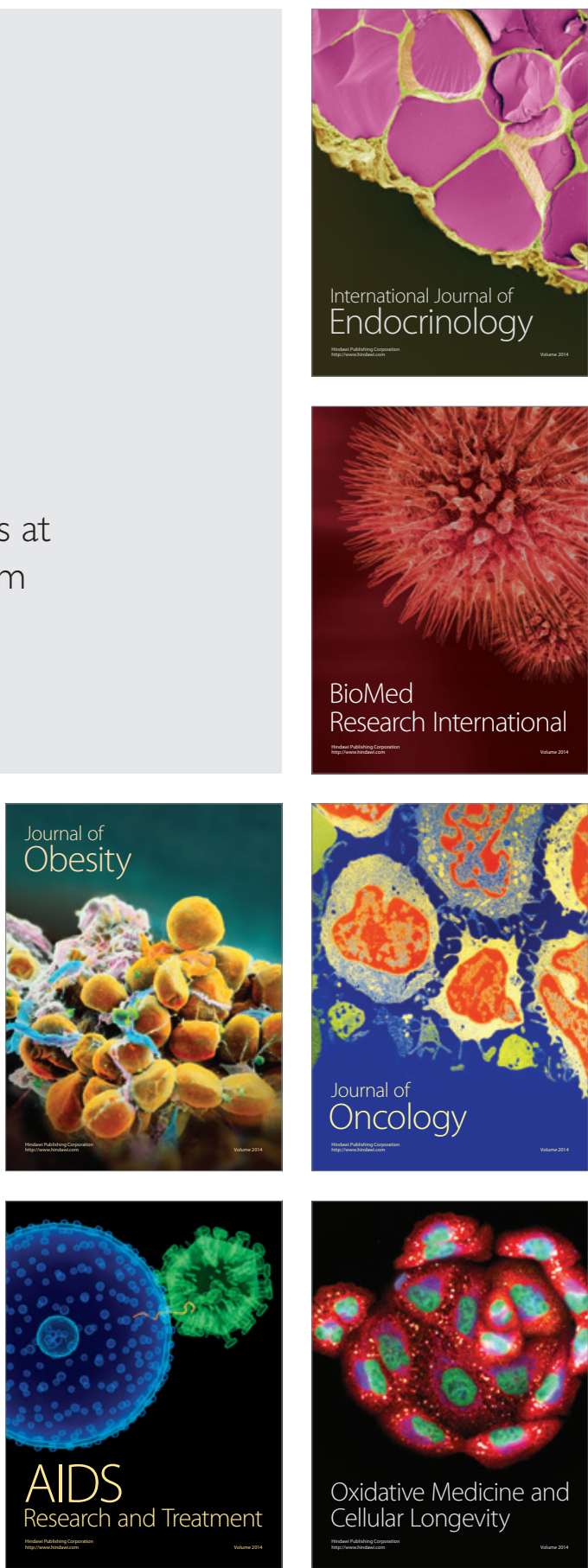